\title{
Distribution and Kinetic Properties of GABAergic Inputs to Layer V Pyramidal Cells in Rat Auditory Cortex
}

\author{
Brenda J. Hefti and Philip H. Smith PH.D. \\ Department of Anatomy, University of Wisconsin Medical School, Madison, WI 53706, USA
}

Received: 27 March 2002; Accepted: 16 July 2002; Online publication: 18 September 2002

\begin{abstract}
Neocortical layer $\mathrm{V}$ is distinguished by both its pyramidal cells and its varied cortical and extracortical projections. Several studies suggest that the layer V pyramidal cell types, intrinsically bursting (IB) and regular spiking (RS) cells, differ both in the circuits in which they participate and in their inhibitory inputs. We quantified differences in inhibitory inputs to RS and IB cells using whole-cell voltage clamp techniques in the auditory cortex. We recorded miniature inhibitory postsynaptic currents (mIPSCs) and spontaneous IPSCs to gain kinetic, amplitude, and frequency information about GABAergic synapses. We then used focal sucrose applications to elicit mIPSC rate increases at the soma or dendrites of both cell types. We also electrically stimulated the axons giving rise to inhibitory synaptic inputs to measure minimally evoked IPSCs occurring at the soma or apical dendrites. We found that spontaneous and evoked IPSCs recorded from the auditory cortex have faster rise and decay kinetics when directly compared with those of the same layer $\mathrm{V}$ cells in other sensory cortical areas. We also found that mIPSCs observed in auditory IB and RS cells are different from one another. RS cell mIPSCs are larger and have faster rises and decays than IB cell mIPSCs, but IB cell mIPSCs occur more frequently. Focal sucrose application showed that most IB cell mIPSCs originate in the dendrites and are subject to dendritic filtering while most RS cell mIPSCs originate at the soma and are
\end{abstract}

Correspondence to: Philip H. Smith - Department of Anatomy • University of Wisconsin Medical School 1300 University Avenue • Madison - WI 53706. Telephone: (608) 262-0291; fax: (608) 2627306; email: Smith@physiology.wisc.edu not filtered. These findings suggest that, first, IB and RS cells process their inputs in fundamentally different ways and, second, auditory cortical RS and IB cells may have specializations that allow them to process inhibitory inputs faster.

Keywords: Auditory cortex, GABA, layer V, kinetics, intrinsically bursting, regular spiking

\section{INTRODUCTION}

The varied cell types and cortical and extracortical targets of layer $\mathrm{V}$ make understanding this lamina important in comprehending cortical circuitry and feedback projections in general. Layer $\mathrm{V}$ contains two pyramidal cell types, based on their in vitro spike responses to depolarizing current: the intrinsically bursting (IB) and the regular spiking (RS) cell. While RS cells are observed in all cortical layers except layer I, IB cells are found only in layer V and the deepest part of layer IV.

IB and RS neurons participate in different, mutually exclusive feedback and feedforward circuits. Pyramidal cells anatomically similar to IB cells project to the thalamus and may be the source of large, specialized inputs to thalamocortical cells in secondary thalamic areas (Games and Winer 1988; Moriizumi and Hattori 1991; Ojima 1994). In addition to their thalamic projections, layer V IB cells are likely the only source of cortical projections to the midbrain and brainstem (Weedman and Ryugo 1996a,b; Doucet et al. 2002). RS cells in layer V probably do not participate in these subcortical projections and com- 
prise the corticocortical (Vaughan 1983; Cipolloni and Peters 1983; Ruttgers et al. 1990; Mascagni et al. 1993) and the corticocaudate (Ojima et al. 1992) projections. This pattern of RS and IB projections is seen in other sensory cortices (Deschenes et al. 1994; Bourassa and Deschenes 1995; Guillery 1995), and is likely a general feature of cortical sensory feedback projections.

Another feature that sets these cell types apart is an apparent difference in their inputs through thalamocortical circuits. In current clamp studies, IB cells appear to have predominantly excitatory responses to stimulation of thalamocortical inputs, while RS cells have mixed excitatory and inhibitory responses (Chagnac-Amitai and Connors 1989; Baranyi et al. 1993; Nunez et al. 1993; Nicoll et al. 1996; Hefti and Smith 2000; Schubert et al. 2001). However, electron microscopic evidence is at odds with this physiological finding in the somatosensory cortex. Serial reconstructions of identified IB and RS neurons reveal no significant differences in the number of inhibitory synaptic sites on IB and RS cell somata (White et al. 1994). This suggests that these numerically similar inputs are not performing the same function in the two cell types during thalamocortical activation. To address this discrepancy, we used whole-cell voltage clamp recordings of spontaneous and evoked IPSCs in IB and RS cells to determine the sources and kinetics of their inhibitory inputs. We have assessed the inhibitory inputs to RS and IB cells in layer $\mathrm{V}$ in several ways. First, we examined miniature and spontaneous IPSCs generated in IB and RS cells. Second, we examined the sources of their inputs using focal applications of sucrose to induce localized increases in presynaptic vesicle release rate. Third, we stimulated single or small numbers of synaptic inputs to individual neurons to examine evoked IPSCs at the cell body and on the dendrites. Finally, because our kinetic measurements suggested auditory cortex IPSCs were kinetically different from those observed previously in other cortices, we compared auditory IPSC kinetics with IPSCs in the same cell populations in visual and somatosensory cortices.

\section{METHODS}

\section{Slice preparation}

All procedures described are in compliance with University of Wisconsin Animal Care and Use Committee regulations. Long-Evans pigmented rats of ages ranging from 18 to 30 days postnatal were used so that more valid comparisons could be made to previous in vivo and in vitro results. No significant age differences were seen in any of the following results. Rats were deeply anesthetized with sodium pento- barbital injected intraperitoneally or with inhaled halothane. After a surgical plane of anesthesia was reached, evident by a lack of response to a painful toe pinch, the animal was decapitated with a guillotine. The dorsal portion of the skull was removed in $4^{\circ} \mathrm{C}$ sucrose saline (described below), saturated with $95 \%$ $\mathrm{O}_{2} / 5 \% \mathrm{CO}_{2}$. A transverse cut was made approximately one-third of the way through the rostrocaudal extent of the cerebral cortex, and the caudal portion of the brain was dissected out of the skull. The brain was placed, cut side down, on a vibratome platform and adhered with cyanoacrylate glue. Transverse sections approximately $400 \mu \mathrm{m}$ thick were cut at depths coinciding with the primary auditory cortex (Tel), the primary visual cortex (Occ1), or the primary somatosensory cortex (Par1). This depth was determined through comparison with sections from the rat brain atlas of Paxinos and Watson (1986). After slicing was completed, each section was cut along the midline from dorsal to ventral with a scalpel. The sections were stored in a holding chamber at $23^{\circ} \mathrm{C}$ in normal saline saturated with $95 \% \mathrm{O}_{2} / 5 \%$

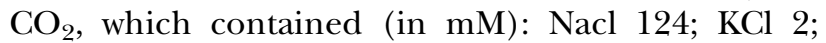
$\mathrm{KH}_{2} \mathrm{PO}_{4} 1.2 ; \mathrm{CaCl}_{2} 2.4 ; \mathrm{MgSO}_{4} 1.3 ; \mathrm{NaHCO}_{3} 26$; and glucose 10 . In sucrose saline (as above), all $\mathrm{NaCl}$ was replaced with sucrose.

\section{Recording techniques}

After a minimum of 1 hour, a slice was removed from the holding chamber and brought to the recording chamber, where it was bathed in normal saline saturated with $95 \% \mathrm{O}_{2} / 5 \% \mathrm{CO}_{2}$ and heated to $34-35^{\circ} \mathrm{C}$ for physiological recording. Pyramidal cells in layer $\mathrm{V}$ were visualized using a video camera (Hamamatsu C2400, Hamamatsu City, Japan) connected to an upright, fixed stage microscope (Zeiss Axioskop, Oberkochen, Germany) equipped with a long working-range water-immersion objective (Zeiss Achroplan $40 \times, 0.75$ n.a.), differential interference contrast optics (Nomarski), and an infrared bandpass filter (Chroma D770/40). Whole-cell recordings were obtained using a patch-clamp amplifier (Axopatch 1D, Axon Instruments, Foster City, CA) and PClamp software (Version 6.1, Axon Instruments). Data were filtered at $5 \mathrm{kHz}$ and sampled at $10 \mathrm{kHz}$ for a number of early experiments ( $n=5 \mathrm{IB}$ and 6 RS cells). However, upon analysis of the preliminary data, we discovered that the IPSCs were faster than predicted. Thereafter, data were filtered at $10 \mathrm{kHz}$ and sampled at $20 \mathrm{kHz}$ (Digidata 1200). When analyzing rise times, only those data sampled at $20 \mathrm{kHz}$ were used, but all data were used for other measurements. All data were stored on a Pentium-based PC. Whole-cell recordings were obtained using standard techniques (Hamill et al. 1981; Edwards et al. 1989). Immediately upon 
breaking into a cell, square voltage pulses in current clamp mode were used to identify the cell's response type based on spike pattern. In the 30-45 seconds before the $\mathrm{CsCl}$ in the intracellular solution obscured the intrinsic membrane properties of the cell, it was often possible to obtain between two and five records, which was more than adequate to identify the response/cell type. In current clamp mode, IB cells consistently fire a burst of action potentials at the beginning of a square current pulse, and RS cells fire only single spikes. In practice, this technique proved successful approximately $75 \%$ of the time to determine cell type. When this method was not successful, histological evidence was used, as described below.

Patch pipettes were pulled using borosilicate glass (Garner Glass, KG-33, 1.7 o.d., 1.1 i.d.), with a Flaming-Brown P-87 horizontal pipette puller. Pipettes were coated with SYLGARD and the tips polished to reduce electrode capacitance. Pipette tips had open tip resistances of 1.5-3.0 $\mathrm{M} \Omega$ when filled with the recording solution, which consisted of (in $\mathrm{mM}$ ): $\mathrm{CsCl}$ 130, NaHEPES 10, MgATP 2, EGTA 1, and 0.5\% Neurobiotin. Access resistances ranged from 6 to $20 \mathrm{M} \Omega$, and then were compensated $80 \%$. Cells were held at $-80 \mathrm{mV}$. $\mathrm{GABA}_{\mathrm{A}}$ currents were isolated by bath application of CNQX $(50 \mu \mathrm{m})$ or DNQX (100 $\mu \mathrm{m})$ and APV $(100 \mu \mathrm{m})$ to block both AMPA and NMDA-mediated currents. To isolate miniature IPSCs, TTX $(2 \mu \mathrm{m})$ was added in addition to the above compounds to block voltage-gated sodium channels. Because cesium was present in the intracellular electrode, $\mathrm{GABA}_{\mathrm{B}}$ receptor-mediated currents were not observed.

Sucrose-evoked mIPSCs were obtained by local application of bath solution containing $0.5 \mathrm{M}$ sucrose using a Picospritzer (General Valve, Fairfield, NJ). Picospritz pipettes were un-SYLGARDED recording electrodes (see above for complete description). Miniature IPSCs were recorded for $500 \mathrm{~ms}$ after sucrose application. An increase in mIPSC rate did not usually occur for approximately $100 \mathrm{~ms}$ after picospritz, but it continued for 400-800 ms postapplication. Only events in the first $400 \mathrm{~ms}$ after application were used for analysis, as this was the period of highest mIPSC rate, and the largest proportion of mIPSCs recorded over that time were the result of the sucrose application and were not spontaneous events. Synaptically evoked IPSCs resulting from axonal activation were obtained using a patch pipette containing bath solution and which was placed within $2-5 \mu \mathrm{m}$ of the cell body or apical dendrite. One pole was placed in the stimulating pipette, and the other was grounded distant from the tissue in the bath. The voltage-generating stimulation unit (Iso-flex, Jerusalem, Israel) was placed within the Faraday cage to reduce stimulas artifacts. A minimally evoked re- sponse was likely elicited when a systematic increase in stimulus strength over a small range led to a decrease in failure rate but not to a systematic increase in IPSC amplitude. We discarded data in which the rising component of the IPSC was not smooth, which might indicate two nonconcurrent inputs or spike initiation. In most cases, IPSC variability was tolerated within an approximately 20-100 pA range, where evoked IPSCs were measured at 100-800 pA total amplitude.

\section{Histology}

As noted above it was not always possible to identify cell type physiologically in current clamp mode before diffusion into the cell of the $\mathrm{CsCl}$ in the intracellular solution made this impossible. However, in approximately $75 \%$ of all cases, between two and five depolarizing square current pulses resulting in either single spikes or bursts were recorded before the cesium in the intracellular solution obscured the recording. In addition, spontaneous single spikes (indicative of RS cells) or spontaneous bursts of spikes (indicative of IB cells) could often be seen extracellularly after a tight seal was obtained but before the membrane was ruptured. Thus, because neither of these methods always provided a conclusive indication of cell type, all cells were processed for histology.

After recording was complete, slices were fixed in $4 \%$ paraformaldehyde in $0.1 \mathrm{M}$ phosphate buffer. They were then cryoprotected and $60 \mu \mathrm{m}$ frozen sections were cut on a freezing microtome and collected in $0.1 \mathrm{M}$ phosphate buffer, $\mathrm{pH}$ 7.4. The sections were incubated in avidin-biotin-HRP complex (ABC kit, Vector Labs, Burlingame, CA). The following day they were rinsed in phosphate buffer and incubated with nickel/cobalt-intensified DAB (Adams 1981). The sections were then mounted, counterstained with cresyl violet, and coverslipped.

Because visualization was most effective near the surface of the slice, most recorded cells were located within approximately $50 \mu \mathrm{m}$ of the tissue surface. In processing, this surface tissue was sometimes damaged or lost, and recovery of cells for anatomical analysis was only successful approximately $60 \%$ of the time. We set four criteria for cell type identification: visual examination of the cell before a seal was attempted, including overall soma size and thickness of the apical dendrite; extracellular spikes seen during and after seal formation; current clamp records using square current pulses, taken immediately after breakin (before the intracellular solution obscured current clamp records); and postfixation anatomical analysis. Two of these criteria were considered definitive for cell type identification based on a previous study (Hefti and Smith 2000): current clamp identification 
immediately after rupturing the cell membrane and postfixation anatomy. The other two criteria, extracellular spikes in cell-attached mode and examination of the cell in vitro, were considered corroborative. For all cells included in this study, at least one definitive and one corroborative criterion were met. For most cells, at least three of the above criteria were met.

Drawings and inspections of injected cells were made using a camera lucida attached to a Zeiss microscope. The location of the cell body relative to the areas of rat cerebral cortex was determined using the atlas of Paxinos and Watson (1986) and the studies in which evoked potential recordings were used to map the location of primary auditory cortex (Barth and Di 1990, 1991; Di and Barth 1992). Cells were identified as RS or IB based on both inspection and measurements of somata and apical dendrites published previously (Hefti and Smith 2000).

\section{Data analysis}

Unless otherwise noted, analyses were done on data that were not additionally filtered offline. Data were analyzed on a Pentium-based PC using Clampfit (Axon Instruments, Union City, CA), Origin (MicroCal, Northampton, MA), and Minitab (Minitab, Inc., State College, PA). Miniature and spontaneous events were analyzed using specialized software written within Origin (Matthew Banks, University of Wiscon$\sin )$. This algorithm measured $t_{\text {rise }}(10-90 \%)$, event amplitude, and interevent interval. Event detection amplitudes were generally set at $\sigma_{\text {noise }}$, as measured in an area of the current trace in which there were no visually detectable events. This algorithm detected approximately $95 \%$ of observable IPSCs. The data were then manually scanned, baseline and peak values were corrected as necessary for individual IPSCs detected by the algorithm, and IPSCs not detected by the algorithm were measured by hand and added to the data set. In order to prevent statistical bias in the data, an approximately equal number of events were used from each individual cell to compile group averages (320-340 events per cell for IB cells, 180-195 events per cell for RS cells).

To look at decay times, a subset (the first 50 events recorded in each cell) of the IPSCs was measured individually to determine decay $\left(\tau_{\text {decay }}\right)$ as fitted to an exponential curve. IPSCs were also aligned (at their peak amplitude) and averaged within individual cells, and the group average was fitted to an exponential decay. Decays were fitted to one or two exponentials. When visual inspection was not sufficient to determine whether the fit was improved by additional exponentials, an $F$-test was performed with a criterion of $p<0.01$, and the smallest number of exponentials at which the fit was not further improved was used.
Currents generated by electrical stimulation of the synaptic inputs to a cell were measured individually in Clampfit or Origin for $t_{\text {rise }}, \tau_{\text {decay }}$, and amplitude. In most cases event latencies were quite short, and some stimulus artifact was still present at the onset of the IPSC. This summation of the artifact and the evoked event usually increased IPSC $10-90 \%$ rise time $\left(t_{\text {rise }}\right)$. To compensate for this error, averaged events in which there was a stimulus artifact but no IPSC (failures) were subtracted from averages of minimally evoked IPSCs and rise times were measured from these artifact-corrected traces.

Because normal distributions could not be assumed for $t_{\text {rise }}, \tau_{\text {decay }}$, amplitude, or interevent interval, all populations were pooled into IB or RS groups and tested for statistical differences using the Kolmogorov-Smirnov (K-S) test at a significance level of $p<0.05$. Unless otherwise stated, all values are mean \pm standard error.

\section{RESULTS}

\section{Basic cell parameters}

Miniature IPSCs were recorded from 15 IB ( $~ 5000$ events) and $16 \mathrm{RS}(\sim 3000$ events) cells in the presence of APV, DNQX, and TTX at holding potentials of $-80 \mathrm{mV}$. APV and DNQX were used to block glutamatergic (excitatory) inputs to the cell, and TTX was used to block voltage-gated sodium channels and to prevent action potentials. The intracellular pipette contained $\mathrm{CsCl}$ to inhibit $\mathrm{GABA}_{B}$ IPSCs, and the $\mathrm{CsCl}$ also chloride-loaded the cell and caused $\mathrm{GABA}_{\mathrm{A}} \mathrm{mI}-$ PSCs to be visible as inward currents at holding potentials of $-80 \mathrm{mV}$. By the addition of these compounds, we were able to observe GABA $_{A}$ IPSCs in isolation. No significant differences were seen between cell types in cell input resistance or cell access resistance. IB cells had a slightly higher whole-cell capacitance ( $14 \mathrm{pF}$ vs. $11 \mathrm{pF}$ for RS cells, K-S test, $p=0.04$ ), most likely due to the larger size of IB cells (Chagnac-Amitai et al. 1990; Kasper et al. 1994; Hefti and Smith 2000). Specific values for all measured parameters can be found in Table 1.

\section{Miniature IPSCs in auditory cortical layer $\checkmark$ pyramidal cells}

In order to accurately measure various features of the mIPSPs, we had to change the amount of offline filtering done on the data to suit the parameter being analyzed. Because of the rapid nature of the mIPSCs in these cells, a low-pass filter cutoff frequency of 10 $\mathrm{kHz}$ was necessary to accurately measure the mIPSC rise and decay kinetics. This filter cutoff made the baseline noise levels quite high, probably due to high- 


\section{TABLE 1}

Comparisons of RS and IB cell miniature and evoked GABA IPSCs $^{a}$

\begin{tabular}{|c|c|c|}
\hline & $R S$ & $I B$ \\
\hline mIPSCs & $0.31 \pm 0.004 \mathrm{~ms}$ & $0.52 \pm 0.005 \mathrm{~ms}^{b}$ \\
\hline$t_{\text {rise }}$ & $\tau_{1}: 1.23 \pm 0.09 \mathrm{~ms}\left(\mathrm{~A}_{1}=0.26\right)$ & $2.62 \pm 0.19 \mathrm{~ms}^{b}$ \\
\hline$\tau_{\text {decay }}$ & $\tau_{2}: 3.71 \pm 0.18 \mathrm{~ms}\left(\mathrm{~A}_{2}=0.68\right)$ & \\
\hline Amplitude & $95.0 \pm 1.1 \mathrm{pA}$ & $58.3 \pm 0.5 \mathrm{pA}^{b}$ \\
\hline IEI & $78.9 \pm 3.2 \mathrm{~ms}$ & $31.9 \pm 0.9 \mathrm{~ms}^{b}$ \\
\hline Sucrose-elicited mIPSCs, soma & $0.29 \pm 0.04 \mathrm{~ms}$ & $0.34 \pm 0.02 \mathrm{~ms}^{b}$ \\
\hline $\begin{array}{l}\tau_{\text {decay }} \\
t_{\text {rise }}\end{array}$ & & \\
\hline Amplitude & $\begin{array}{c}\tau_{1}: 1.18 \pm 0.08 \mathrm{~ms} \\
\tau_{2}: 3.56 \pm 0.22 \mathrm{~ms} \\
93.7 \pm 3.9 \mathrm{pA}\end{array}$ & $\begin{array}{l}2.54 \pm 0.22 \mathrm{~ms}^{b} \\
69.8 \pm 1.9 \mathrm{pA}^{b, c}\end{array}$ \\
\hline $\begin{array}{l}\text { Sucrose-elicited mIPSCs, dendrite } \\
t_{\text {rise }} \\
\tau_{\text {decav }}\end{array}$ & $0.51 \pm 0.07 \mathrm{~ms}^{c}$ & $0.53 \pm 0.09 \mathrm{~ms}$ \\
\hline Amplitude & $\begin{array}{l}2.69 \pm 0.33 \mathrm{~ms}^{c} \\
76.2 \pm 2.6 \mathrm{pA}^{c}\end{array}$ & $\begin{array}{l}2.67 \pm 0.32 \mathrm{~ms} \\
64.0 \pm 1.8 \mathrm{pA}\end{array}$ \\
\hline $\begin{array}{l}\text { Evoked IPSCs, soma } \\
t_{\text {rise }}\end{array}$ & $0.33 \pm 0.02 \mathrm{~ms}$ & $0.39 \pm 0.05 \mathrm{~ms}^{b, c}$ \\
\hline $\begin{array}{l}\tau_{\text {decay }} \\
\text { Amplitude }\end{array}$ & $\begin{aligned} 2.93 & \pm 0.32 \mathrm{~ms} \\
202.8 & \pm 36.6 \mathrm{pA}\end{aligned}$ & $\begin{aligned} 2.83 & \pm 0.23 \mathrm{~ms} \\
197 & \pm 29.6 \mathrm{pA}\end{aligned}$ \\
\hline $\begin{array}{l}\text { Evoked IPSCs, dendrite } \\
t_{\text {rise }}\end{array}$ & $0.67 \pm 0.08 \mathrm{~ms}^{c}$ & $0.71 \pm 0.09 \mathrm{~ms}^{c}$ \\
\hline $\begin{array}{l}\tau_{\text {decay }} \\
\text { Amplitude }\end{array}$ & $\begin{aligned} 5.4 & \pm 1.2 \mathrm{~ms} \\
167.2 & \pm 43.5 \mathrm{pA}\end{aligned}$ & $\begin{aligned} 4.6 & \pm 0.83 \mathrm{~ms}^{c} \\
179.2 & \pm 23.6 \mathrm{pA}\end{aligned}$ \\
\hline
\end{tabular}

${ }^{a}$ Values are mean \pm standard error. RS, regular spiking; IB, intrinsically bursting; mIPSC, miniature inhibitory postsynaptic current.

${ }^{b}$ Statistically significant difference of $p<0.05$ using the Kolmogorov-Smirnov test when comparing RS cell values to IB cell values.

'Statistically significant difference of $p<0.05$ using the Kolmogorov-Smirnov test when comparing sucrose-elicited mIPSCs or evoked IPSCs to control mIPSCs.

frequency cell noise. Using this low-pass filter we noted some interesting differences in the miniature IPSCs from the two cell types: RS cell IPSCs were significantly faster than IB cell IPSCs (K-S test, $p<$ 0.01 , Fig. 1). Decay times $\left(\tau_{\text {decay }}\right)$ likewise differed between cell types (Fig. 2). IB cell mIPSCs were usually fitted accurately with one time constant $(n=14$ of 15 cells). Additional time constants did not significantly improve the fit ( $F$-test, $p>0.01)$. RS cell decays could be fitted to a single exponential; however, fits were significantly improved using two time constants ( $F$-test, $p<0.01, n=16$ of 16 cells). IB cell decay times were significantly longer than the first $\tau_{\text {decay }}$ of RS cells (K-S test, $p<0.01)$, but significantly shorter than the second $\tau_{\text {decay }}$ of RS cells (K-S test, $p<0.01$; Fig. 2 ). This held true for both comparisons of individual events in IB and RS cells and comparisons of averages of 30-60 events per cell.

At the noise level present in the $10 \mathrm{kHz}$ recordings, it was difficult to detect events that were smaller than approximately $25 \mathrm{pA}$, possibly biasing both amplitude and frequency measurements and making quantitative statements about either parameter impossible. For a more accurate measurement of IPSC rate and amplitude in IB and RS cells, we did the following analyses. To measure IPSC rates it was first necessary to determine whether all events were detected at the holding potential $(-80 \mathrm{mV})$. To do this, events were recorded at voltages from -120 to $+40 \mathrm{mV}$ and then filtered at $2 \mathrm{kHz}$ to reduce the noise and allow detection of smaller events, down to approximately 8-10 pA. This analysis indicated that approximately 20 $22 \%$ of all detectable events were obscured by high frequency noise in the original $10 \mathrm{kHz}$ recordings. The number of detected events at $2 \mathrm{kHz}$ was then plotted against voltage for three cells (Fig. 3), with inward events plotted to the left of zero (negative) and outward events to the right of zero (positive). The plateau, reached at approximately -70 to $-80 \mathrm{mV}$, indicated that in both cell types all events recordable at the soma were being detected. Once we were confident all events were detectable at the holding potential, we used the filtered traces from $5 \mathrm{IB}$ and 5 RS cells. When we measured miniature IPSC interevent intervals (IEI) from these cells, using filtered data that allowed us to count all mIPSCs, we found that IB cells received mIPSCs more frequently than RS cells (Fig. 4A). The IEI of mIPSCs recorded at the somata of IB cells was $32 \mathrm{~ms}$, giving a mIPSC rate of approximately $31 \mathrm{~Hz}$. The IEI of mIPSCs in RS cells 
A
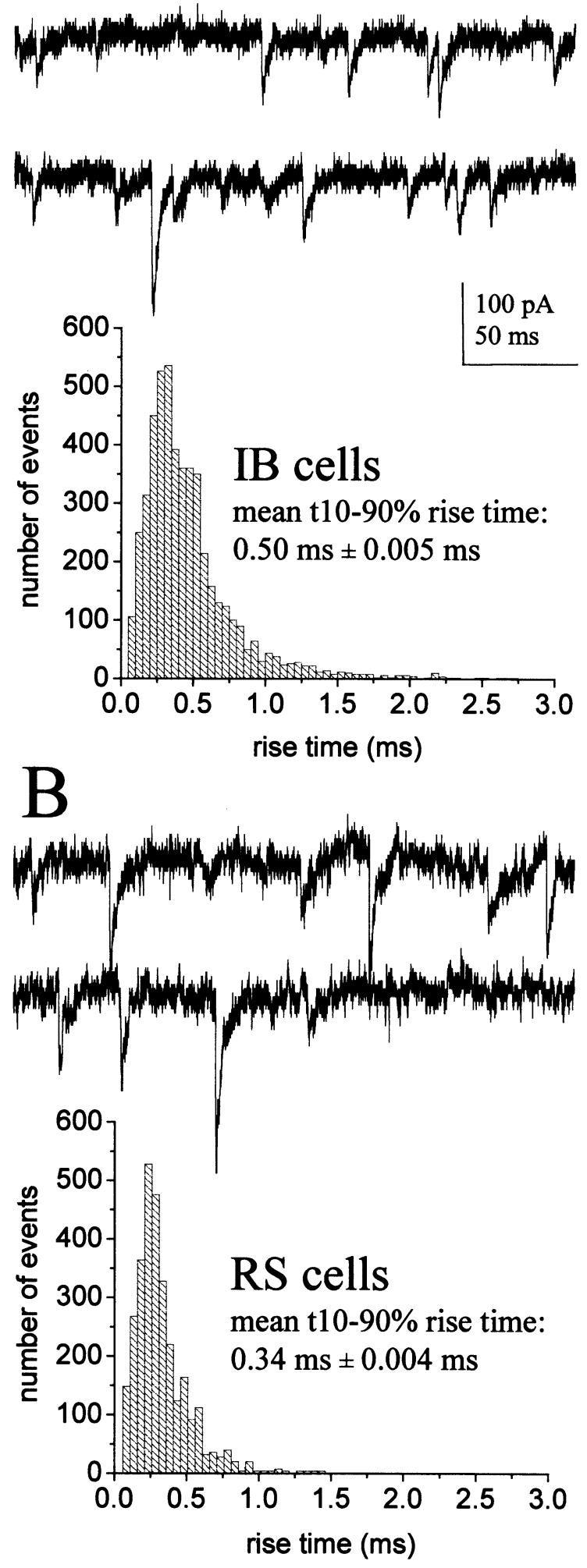

FIG. 1. IB and RS cells have different 10-90 rise times. A. (Top) Miniature IPSCs recorded from an anatomically and physiologically identified IB cell. (Below) Histogram of all mIPSCs recorded from 15 IB cells ( $\sim 5000$ events). B. (Top) Miniature IPSCs recorded from a physiologically and anatomically identified RScell. (Below) Histogram of all mIPSCs recorded from 16 RS cells ( 3000 events). Scale bars in $\mathbf{A}$ apply to traces in both $\mathbf{A}$ and $\mathbf{B}$. was $79 \mathrm{~ms}$, giving an event rate of $13 \mathrm{~Hz}$. This measurement had very high variability in the pooled data (Fig. 4A), but despite this, the result was statistically significant (K-S test, $p<0.01)$. This was a surprising result given the following information: It has been shown in vitro that individual synapses with high miniature synaptic activity rates (rates which are independent of spike activity) also tend to show a higher probability of spike-induced transmitter release, that is, a lower failure rate (Prange and Murphy 1999). Our previous findings in the auditory cortex had shown that RS cells receive a considerable thalamocortically activated inhibitory input while IB cells receive little or none (Hefti and Smith 2000). From this we reasoned that perhaps our observed differences in the shock-activated inhibitory inputs to the two layer V pyramidal cell populations (Hefti and Smith 2000) might indicate differences in failure rates between the inhibitory inputs to the two cell types that could be reflected in the mIPSC rates displayed by the two cell types. We had thus predicted that the mEPSC rate would be higher in the RS cells. Our present findings indicate that the opposite is true.

Quantitative analysis of event amplitudes was also impossible using the original (20 $\mathrm{kHz}$ sampling rate) traces, because amplitude averages would exclude all events below approximately $25 \mathrm{pA}$. Using the data sampled at $20 \mathrm{kHz}$, histograms of peak amplitude (Fig. 4B) indicate that most of the events occur in the range of 40-70 pA in both cell types but that RS cells have more large-amplitude events, as illustrated by the extended right-hand tail in the RS cell histogram that is absent in the IB cell histogram. Overall, differences in mIPSC amplitude were significant, indicating that RS cell mIPSCs were significantly larger than IB cell mIPSCs (K-S test, $p<0.01$; Fig. 4B). This same amplitude analysis was also performed on data filtered offline at $2 \mathrm{kHz}$, and the results were similar. We found that approximately the same percentage of the total number of events was not detected in each cell type (22\% for IB, $20 \%$ for RS). Therefore, it is likely that differences seen without inclusion of these events would remain when these events are added. Using the data filtered at $2 \mathrm{kHz}$, amplitudes of individual mIPSCs were smaller because mIPSC peaks were filtered, and average amplitudes were also smaller because of both peak filtering and the addition of small-amplitude events. Overall, however, RS cells still had far larger mIPSCs than IB cells (78 vs. 48 pA, $p<0.01$; data not shown).

\section{Miniature IPSCs in visual and somatosensory} cortical layer $\mathrm{V}$ cells

We were surprised to note that the kinetics of mIPSCs observed in the auditory cortex were faster than re- 

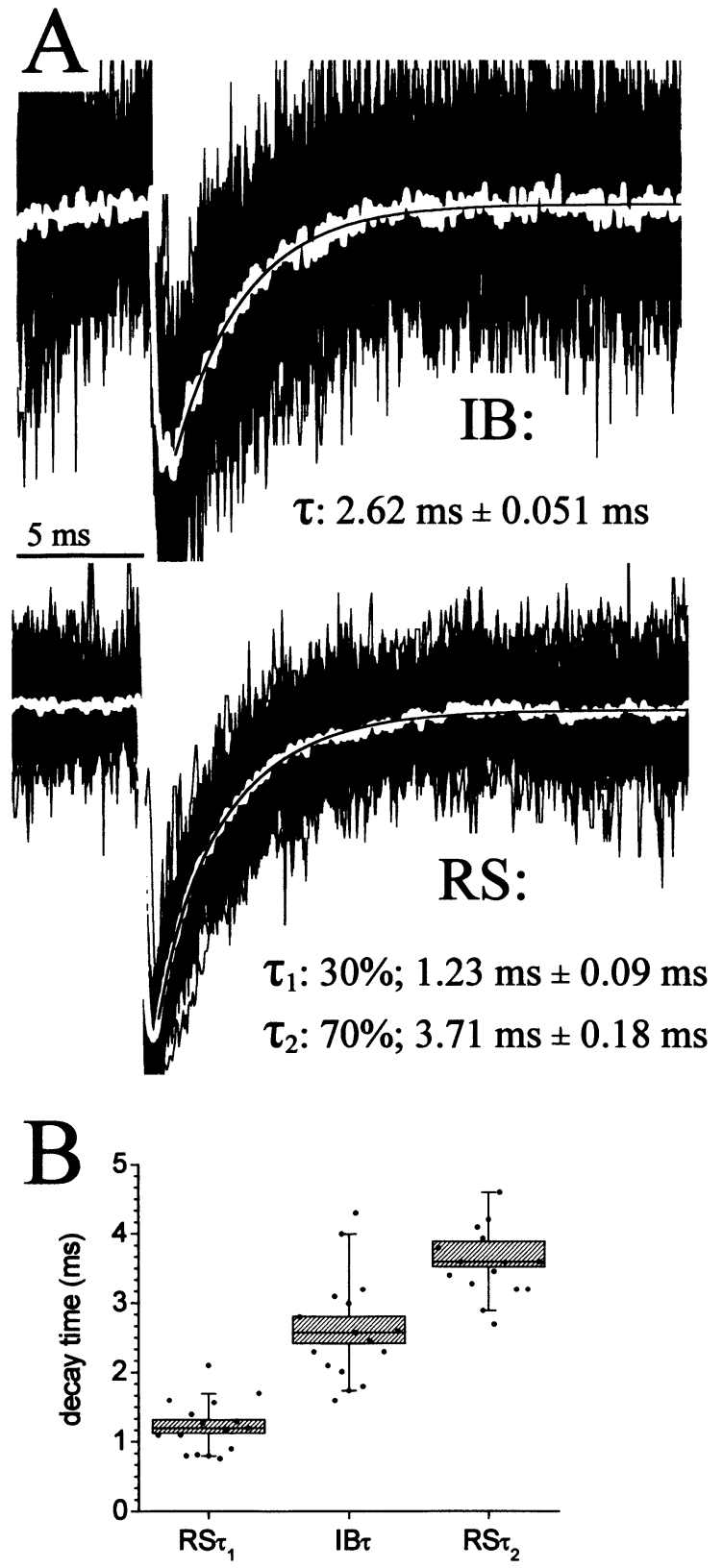

FIG. 2. RS and IB cells have different decay rates and kinetics. A. In black, plot of 200 IB (top) and RS (below) cell mIPSCs normalized for size and aligned at their peaks. In white, average plot of the events. In black, superimposed on white average, is the best fit for each decay curve. IB cell mIPSCs fit a single exponential decay most accurately. Additional exponentials did not improve fit. RS cell mlPSCs fit a decay curve with two exponentials best, and this fit was significantly better than a single exponential fit ( $F$-test, $p<0.01)$. B. Box plots of average decay time measured in $15 \mathrm{IB}$ and 16 RS cells. Individual dots are decay times for a given cell, the shaded boxrepresents one standard error, and the bars represent 5-95 confidence bands. All three values are significantly different from each other.

ported in previous visual (Xiang et al. 1998) or somatosensory (Salin and Prince 1996) cortical experiments. Because recording temperatures, filtering, and sampling rates were not completely consistent

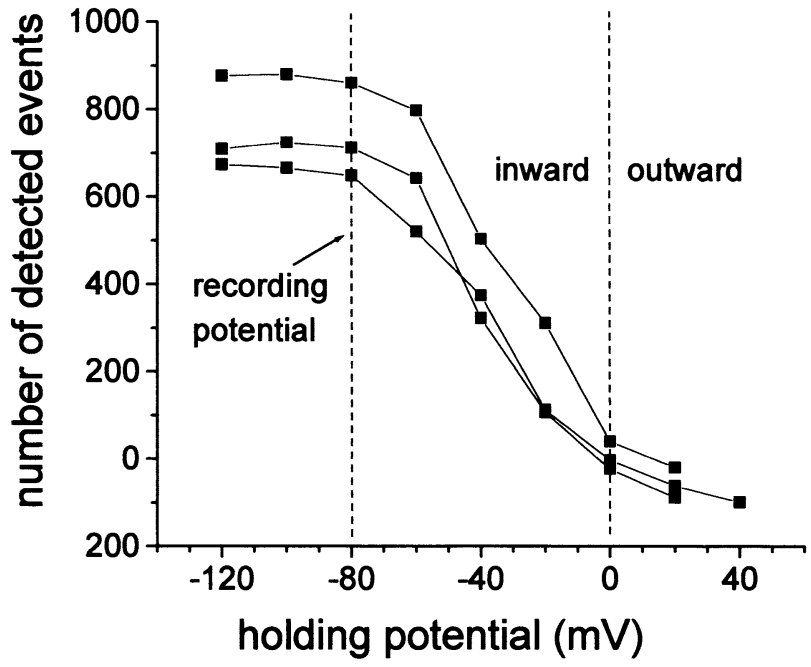

FIG. 3. All detectable events are visible at the chosen recording potential of $-80 \mathrm{mV}$. Plotted is number of events per fixed unit of time (30 s) versus holding potential for 3 cells. Current flow generated by events reversed from inward to outward in the range of -10 to $+10 \mathrm{mV}$ (right dotted line). The plateau of all curves in the range of -70 to $-80 \mathrm{mV}$ indicates that all events occurring in the cells are visible at the recording potential of $-80 \mathrm{mV}$ (left dotted line).

with those used in the current results, we recorded mIPSCs from IB and RS cells in these cortical areas in order to compare them with auditory cortex (Table 2).

Our recordings from all three cortical areas under consistent recording conditions showed the following: (1) Like the auditory cortex, the mIPSCs in IB and RS cell populations in visual and somatosensory cortices differed in their kinetics, frequency, and amplitude. Rise times in IB cells were slower than RS cell rise times in both cortical areas. Decay times and kinetics also differed between cell types in visual and somatosensory cortices. Like in the auditory cortex, RS cell decay times were best fit to two exponentials, while IB cell decay times were fit with a single exponential (Table 2). IB cell mIPSCs were smaller than RS cell mIPSCs in both visual and somatosensory cortices, and they occurred more frequently, on average. While specific values varied, consistent differences between IB and RS cell mIPSCs were seen in all cortical areas studied. (2) The overall kinetics of mIPSCs in the auditory cortex were faster than those in the other cortical areas, particularly the decay times (Fig. 5). The rise time differences were fairly small. Rise times in visual and somatosensory IB and RS cells, while significantly different from those values observed in auditory cortex, differed by less than $90 \mu \mathrm{s}$, or $25 \%$, between cortical areas. However, decay times were very different between cortical areas, differing by up to $700 \%$. Among RS cells, decay times fit best to two exponentials in all cortical areas. Both the first and the second time constants were shortest in auditory RS cells and longest in visual cortex cells, with 

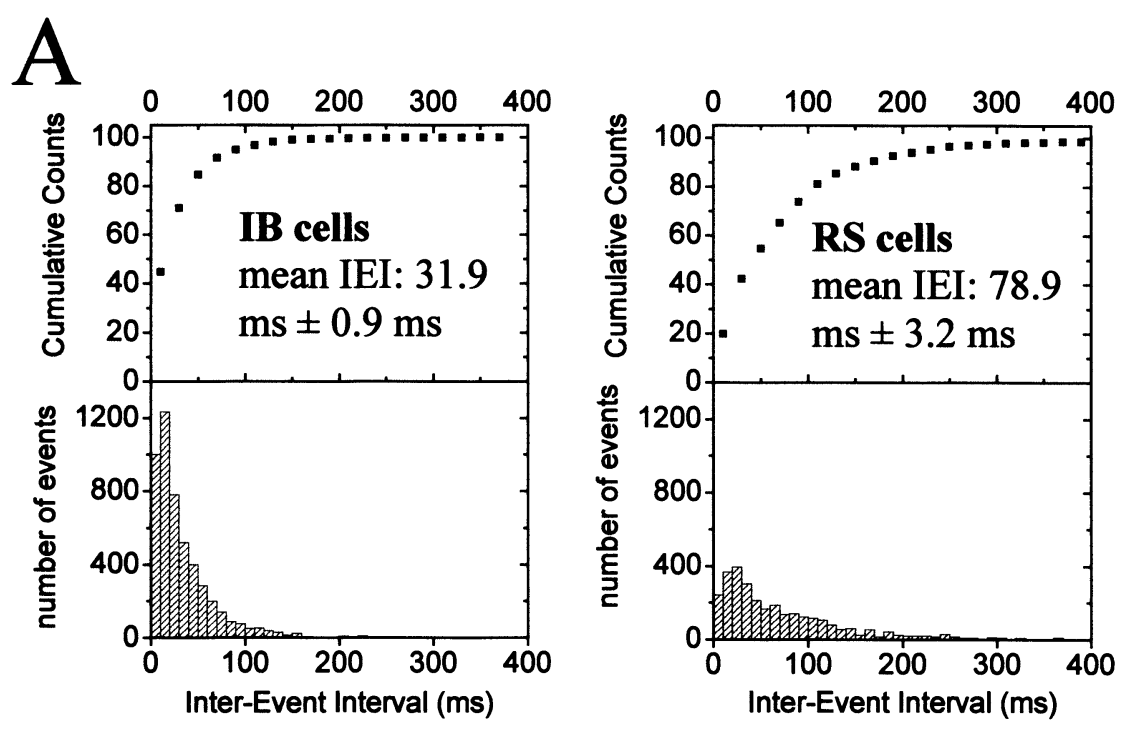

B
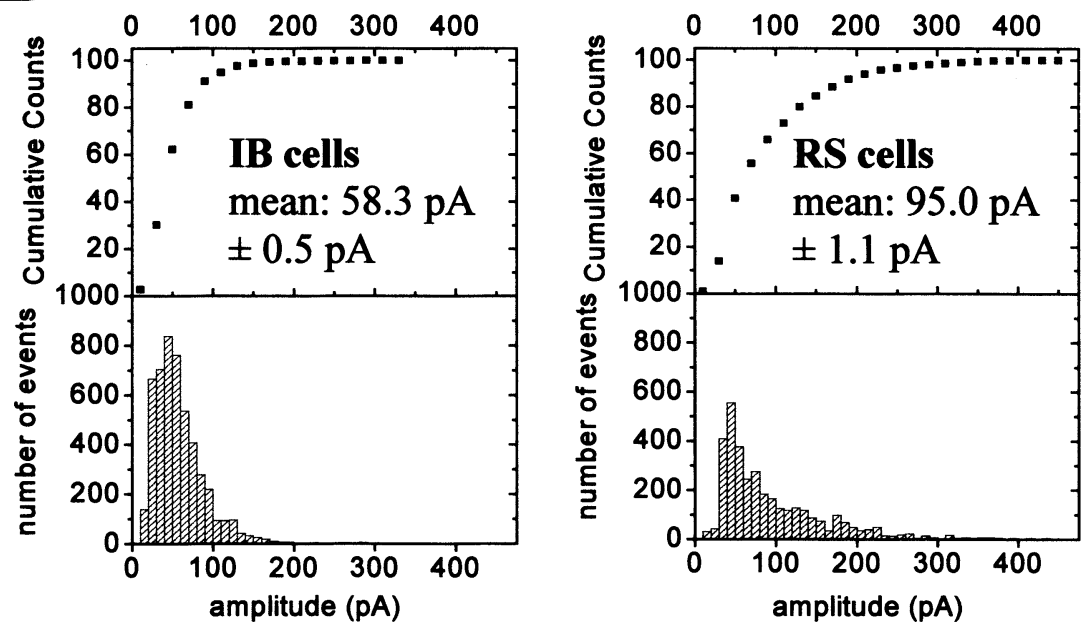

FIG. 4. A. IB and RS neuron mIPSCs have different interevent intervals. (Left) IB cell histogram and cumulative probability curve of mIPSC interevent interval. (Right) RS cell histogram and cumulative probability curve of mIPSC interevent interval. Note extended tail of RS cell cumulative probability plot. B. IB and RS neuron mIPSCs have different amplitudes. (Left) IB cell histogram (below) and cumulative probability curve of mIPSC amplitude. (Right) RS cell histogram (below) and cumulative probability curve of mIPSC amplitude. Both cells had histogram peaks at 60-80 pA, but note extended tail of RS cell cumulative probability plot.

an intermediate value in somatosensory cortex cells. IB cell decay constants were fit with a single exponential; adding a second exponential did not significantly improve fits. Similar to RS cells, auditory IB cells had the fastest decays, followed by somatosensory IB cells, and visual cortex IB cells had the slowest decay times.

\section{Spontaneous IPSCs in auditory cortical layer V} pyramidal cells

Spontaneous IPSCs (sIPSCs) were recorded in much the same way as mIPSCs, except that TTX was eliminated from the extracellular solution to allow the generation of action potentials on axons in the slice and the subsequent generation of spike-evoked synaptic events at their terminals ( $n=7$ IB cells, $n=7 \mathrm{RS}$ cells). No significant kinetic differences were seen between spontaneous and miniature IPSCs. Rise times and decay times were similar within cell type and maintained statistical significance when IB and RS cells were compared. As with mIPSCs, IB cell sIPSCs were slower and smaller than RS cell sIPSCs.

The average amplitude of spontaneous events was increased in both cell types (K-S test, $p<0.01$ both cell types) as compared with mIPSCs. The average interevent interval (IEI) also decreased in both cell types (K-S test, $p<0.01$, both cell types) leading to an increased total IPSC frequency as recorded at the soma. In RS cells, average IEI was $27.5 \mathrm{~ms}$, corresponding to a sIPSC rate of $36 \mathrm{~Hz}$. IB cell IEI was similar at $28.5 \mathrm{~ms}$ and $35 \mathrm{~Hz}$. There was no significant difference between the sIPSC rates of IB and RS cells.

When compared with mIPSC results, we found that the rate of sIPSCs was significantly higher than the rate of mIPSCs in RS cells but not in IB cells. This would suggest that virtually no action-potential-dependent events, which might provide tonic inhibitory influences, are occurring in IB cells. However, mI- 
TABLE 2

Comparisons of RS and IB cells in primary visual and somatosensory cortices to auditory cortical RS and IB cells ${ }^{a}$

\begin{tabular}{|c|c|c|c|c|}
\hline & \multicolumn{2}{|c|}{ RS cells } & \multicolumn{2}{|c|}{ IB cells } \\
\hline & Rise & Decay & Rise & Decay \\
\hline Auditory cortex & $\begin{array}{l}0.31 \pm 0.004 \mathrm{~ms} \\
(n=16)\end{array}$ & $\begin{array}{l}\tau_{1}: 1.23 \pm 0.09 \mathrm{~ms} \\
\left(A_{1}=0.26\right) \\
\tau_{2}: 3.71 \pm 0.18 \mathrm{~ms} \\
\left(A_{2}=0.68\right)\end{array}$ & $\begin{array}{l}0.52 \pm 0.005 \mathrm{~ms} \\
(n=15)\end{array}$ & $2.62 \pm 0.19 \mathrm{~ms}$ \\
\hline Visual cortex & $\begin{array}{l}0.35 \pm 0.01 \mathrm{~ms} \\
(n=4)\end{array}$ & $\begin{array}{l}\tau_{1}: 2.00 \pm 0.06 \mathrm{~ms}^{b} \\
\left(A_{1}=0.66\right) \\
\tau_{2}: 28.52 \pm 4.18 \mathrm{~ms}^{b} \\
\left(A_{2}=0.31\right)\end{array}$ & $\begin{array}{l}0.56 \pm 0.01 \mathrm{~ms}^{b} \\
(n=4)\end{array}$ & $7.23 \pm 0.09 \mathrm{~ms}^{b}$ \\
\hline Somato-sensory cortex & $\begin{array}{l}0.39 \pm 0.01 \mathrm{~ms}^{b} \\
(n=4)\end{array}$ & $\begin{array}{l}\tau_{1}: 1.49 \pm 0.15 \mathrm{~ms}^{b} \\
\left(A_{1}=0.35\right) \\
\tau_{2}: 5.45 \pm 0.32 \mathrm{~ms}^{b} \\
\left(A_{2}=0.61\right)\end{array}$ & $\begin{array}{l}0.47 \pm 0.009 \mathrm{~ms}^{b} \\
(n=5)\end{array}$ & $4.45 \pm 0.16 \mathrm{~ms}$ \\
\hline
\end{tabular}

${ }^{a}$ Values are mean \pm standard error. RS, regular spiking; IB, intrinsically bursting; mIPSC, miniature inhibitory postsynaptic current.

${ }^{b}$ Statistically significant difference of $p<0.05$ using the Kolmogorov-Smirnov test when comparing RS cell values to IB cell values.

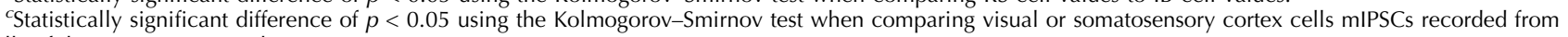
cells of the same type in auditory cortex.

\section{A}

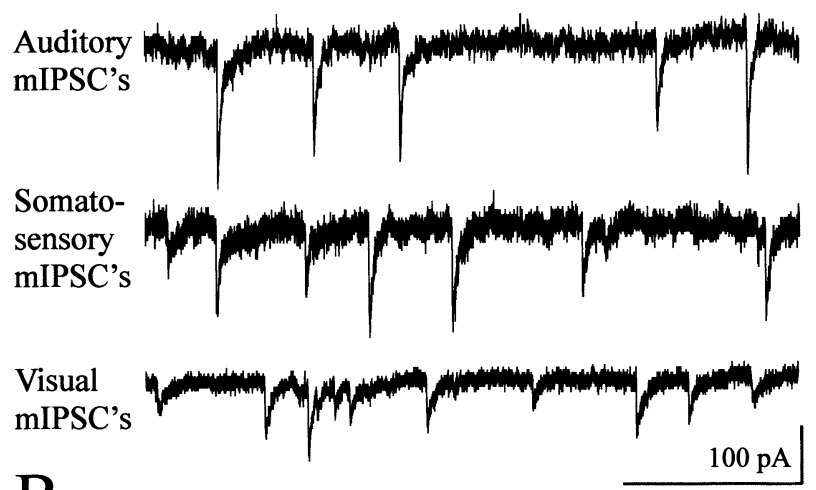

B
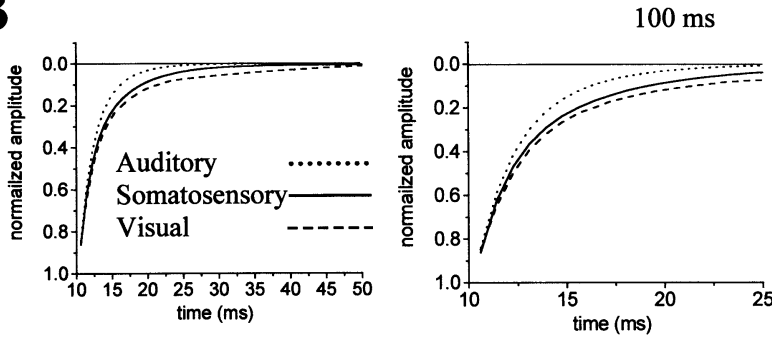

FIG. 5. Comparison of RS cell mIPSCs in auditory, somatosensory, and visual cortices. A. Examples of mIPSCs recorded from each sensory cortical area. Differences in mIPSC kinetics are visible even among individual events. B. (Left) exponential fits of 200 normalized events in each sensory cortical area. (Right) Same plot with shorter time scale showing the point between 20 and $25 \mathrm{~ms}$ at which, on average, auditory cortical mIPSCs decay to zero. All decays were best fit to two exponentials and were as follows; auditory cortex (dotted line): $\tau_{1}: 1.23 \pm 0.09 \mathrm{~ms}\left(A_{1}=0.26\right) \tau_{2}: 3.71 \pm 0.18 \mathrm{~ms}$ $\left(A_{2}=0.68\right)$; somatosensory cortex (solid line): $\tau_{1}: 1.49 \pm 0.15 \mathrm{~ms}$. $\left(A_{1}=0.35\right) \tau_{2}: 5.45 \pm 0.32 \mathrm{~ms}\left(A_{2}=0.61\right)$; visual cortex (dashed line): $\quad \tau_{1}: \quad 2.00 \pm 0.06 \mathrm{~ms} \quad\left(A_{1}=0.66\right) \quad \tau_{2}: 28.52 \pm 4.18 \mathrm{~ms}$ $\left(A_{2}=0.31\right)$.
PSCs and sIPSCs were never both recorded in the same cell, making this result tentative.

\section{Sucrose-evoked IPSCs at the soma and distal apical dendrite}

An important feature of synaptic inputs, which may give some indication of function, is their location on the postsynaptic cell. Thus, we were interested in determining the location of the inhibitory synapses on the two pyramidal cell types. One simple measure that can be made is to plot the amplitude of the synaptic event versus its rise time. The thought is that smaller events are such because they are farther out on the dendritic tree and further from the recording sight, and there should be a positive correlation with the small size and slower kinetics because of the filtering properties of the larger amount of membrane between synapse and recording site. When we did this analysis, we found no correlation for RS cells and a weak negative correlation for IB cells. Recent evidence (Bekkers and Stevens 1996) indicates that this method may not be a reliable measure and that it is necessary to directly stimulate the synapses at a particular location on the cell. Focal sucrose application has been used in a number of preparations (Vyklicky et al. 1991; Bekkers and Stevens 1995, 1996; Rosemund and Stevens 1996; Cheng and Miyamoto 1999) to increase the rate of spontaneous vesicle fusion and neurotransmitter release at the presynaptic terminals in a confined region of the postsynaptic cell membrane. This leads to a focal increase in mIPSC rate postsynaptically. This tool allows us to examine more 


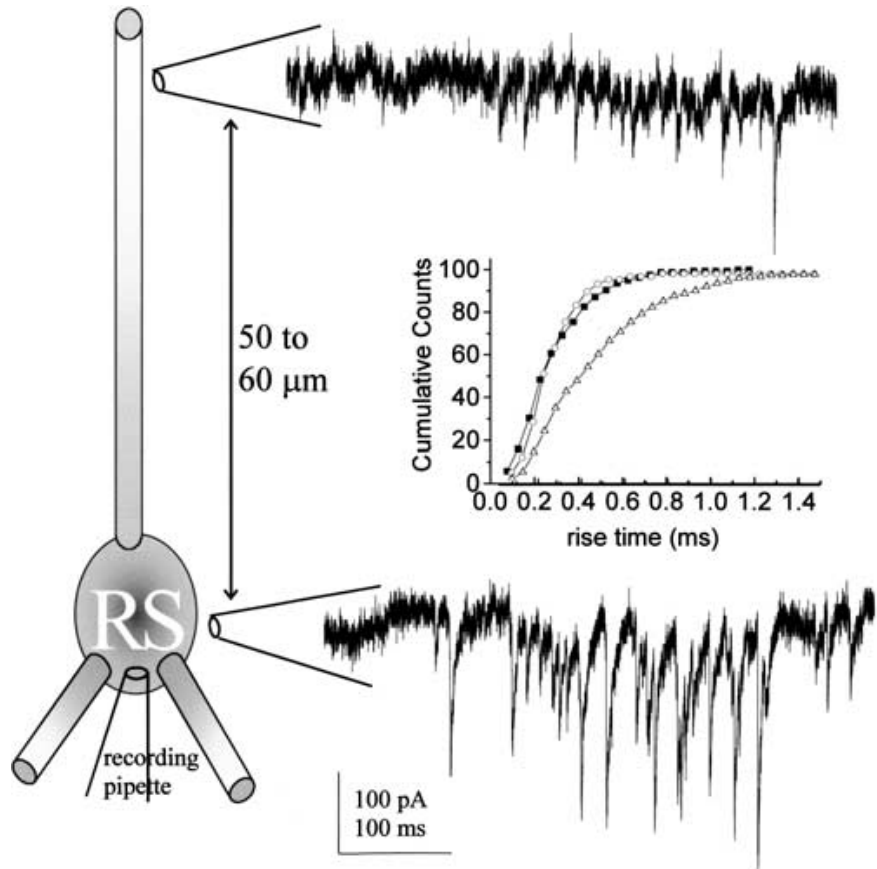

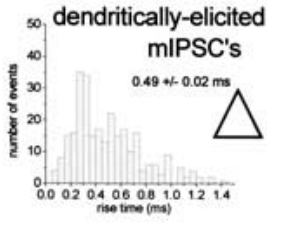
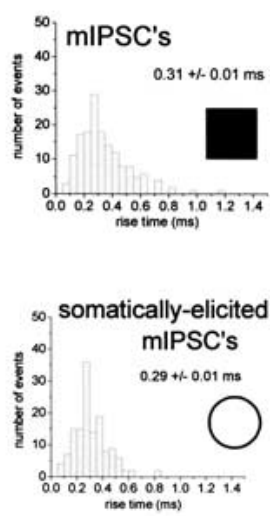

FIG. 6. RS cell mIPSCs are similar to mIPSCs evoked by sucrose at the soma. (Left) Schematic of an RS pyramidal cell showing the position of the recording electrode and sucrose application electrodes. An example of mIPSCs evoked from the apical dendrite (top) or the soma (bottom) of an RS cell is shown adjacent to the sucrose application electrodes generating the response. (Center) Cumulative probability curves of RS cell mIPSC rise times. (Right) Histograms of mIPSC rise times from an individual RS cell. Dendritic mIPSCs (triangle) were significantly slower than both somatic mIPSCs (circle) and control mIPSCs (filled square) within this cell. Somatic and control mIPSC rise times were not statistically different within this cell. Similar results were obtained from all comparisons of somatic and dendritic mIPSCs to control mIPSCs within each individual cell ( $n=8$ RS cells). directly the kinetic properties of mIPSCs occurring in a specific region of the cell, and it can also give information about dendritic filtering. In these experiments, rats at the younger end of the age range (P18-23) were used because, as the rats aged, it became more difficult to visualize the apical dendrite.

Sucrose was pressure-ejected (using a picospritzer) at a pressure of $10-15 \mathrm{mmHg}$ for $30-50 \mathrm{~ms}$ at the soma ( $n=11 \mathrm{IB}, \mathrm{n}=12 \mathrm{RS}$ ) and then at the apical dendrite at a distance of 50-60 $\mu \mathrm{m}$ from the soma ( $n=9 \mathrm{IB}, n=8 \mathrm{RS})$. The picospritz pipette was placed within $2-4 \mu \mathrm{m}$ of target area for more focal application. In a few cells $(n=2 \mathrm{IB}, n=4 \mathrm{RS})$, data were obtained only from the soma before the recording deteriorated. These data were included in the analysis. Measurements from the apical dendrite were used only if data was also obtained from the soma, because without data about somatic mIPSCs within that cell, comparisons might be less reliable.

Sucrose-evoked mIPSCs from the soma and apical dendrite were compared with control mIPSCs in RS cells (Fig. 6). Rise times of these sucrose-evoked RS cell mIPSCs originating at the soma were not statistically different from those recorded in control conditions indicating that the spontaneous mIPSPs from these cells were on the cell body. Sucrose-elicited somatic mIPSCs were somewhat larger than control mIPSCs (K-S test, $p<0.01)$. In contrast, RS cell mIPSCs arising at 50-60 $\mu \mathrm{m}$ away from the soma on the apical dendrite had much slower rise and decay kinetics than either control mIPSCs or sucrose-elicited somatic mIPSCs (K-S test, $p<0.01$, both cases), indicating that the spontaneous mIPSPs did not arise here. Sucrose-elicited dendritic mIPSCs were also smaller than somatic or control mIPSCs (K-S test, $p<$ $0.01)$.

IB cell mIPSCs were also compared under control conditions, when evoked at the soma, and when evoked 50-60 $\mu \mathrm{m}$ from the cell body on the apical dendrite (Fig. 7). IB cell mIPSCs, sucrose-evoked from somatic synapses, had significantly faster rise times than mIPSCs recorded under control conditions (K-S test, $p<0.01)$. Somatic mIPSCs were also larger in amplitude than those recorded in control conditions (K-S test, $p<0.01$ ). Miniature IPSCs, sucrose-evoked from synapses 50-60 $\mu \mathrm{m}$ from the soma on the apical dendrite, were statistically indistinguishable from control mIPSCs in rise time and amplitude, indicating that the location of spontaneous mIPSPs in these cells were more likely to be dendritic. As expected, dendritic mIPSCs were significantly slower than somatic mIPSCs, and smaller in amplitude. These data indicate that the spontaneous IPSCs we record from RS cells arise from somatic synapses, while in IB cells spontaneous IPSCs arise from proximal dendritic synapses.

Synaptically evoked IPSCs at the soma and at locations along the apical dendrites

Miniature and spontaneous IPSCs can give useful information about the properties of individual preand postsynaptic sites, but they give less information about the synaptic inputs reaching the cell. For this reason, we recorded minimally evoked IPSCs at several areas on the cell body and apical dendrite. Af- 


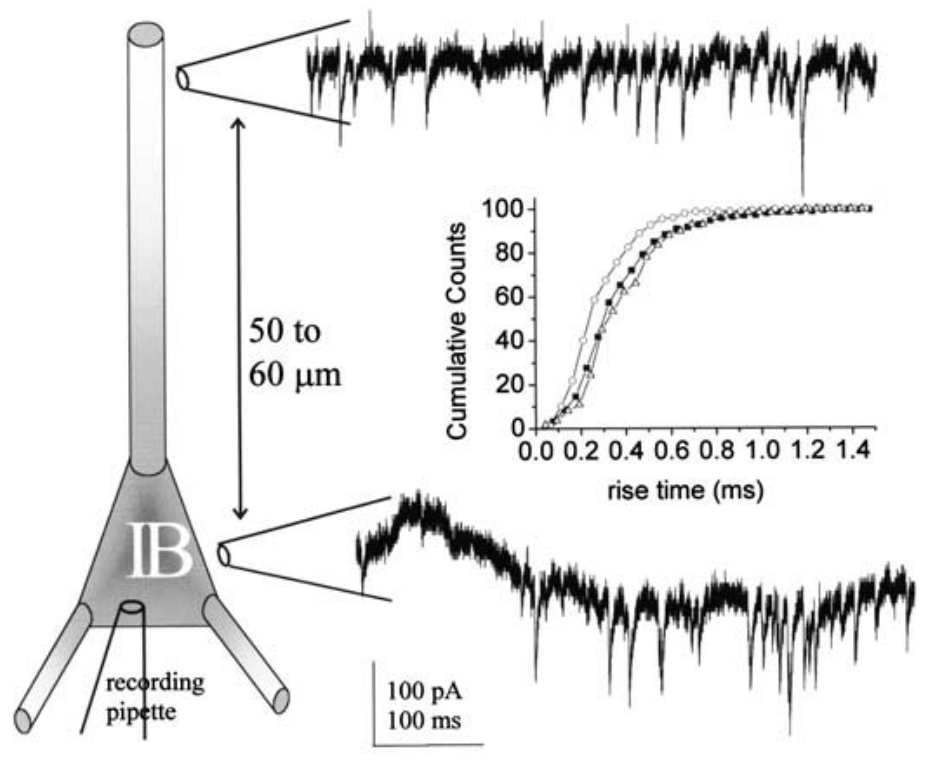

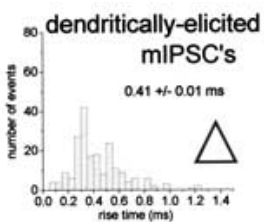
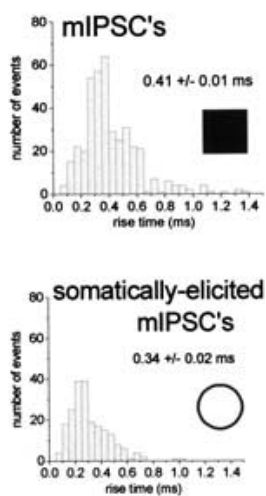

FIG. 7. IB cell mIPSCs are similar to mIPSCs evoked by sucrose distal from the soma on the apical dendrite. (Left) Schematic of an IB pyramidal cell showing the position of the recording electrode and sucrose application electrodes. An example of mIPSCs evoked from the apical dendrite (top) or the soma (bottom) of an IB cell is shown adjacent to the sucrose application electrodes generating the response. (Center) Cumulative probability curves of IB cell mIPSC rise times. (Right) Histograms of mIPSC rise times arising from a single IB cell. Somatic mIPSCs (circle) were significantly faster than both dendritic mIPSCs (triangle) and control mIPSCs (filled square) within this cell. Dendritic and control mIPSC rise times were not statistically different within this cell. Similar results were obtained from all comparisons of somatic and dendritic mIPSCs to control mIPSCs within each individual cell $(n=9$ IB cells). ferent axons were stimulated very close (less than 5 $\mu \mathrm{m})$ to the cell body or apical dendritic membrane (Table 1). Using this method, we attempted to maximize the probability that the stimulated afferent axons had synapses with the recorded cell near the stimulation site. Stimulus strength was started very low and increased at very small intervals in order to stimulate single fibers or very small numbers of fibers. As in the sucrose-evoked IPSC experiments, rats in the range of P18-23 were used because of better visualization of the apical dendrite.

Overall, while RS cell-evoked IPSCs were larger than mIPSCs or sIPSCs, their kinetics, including both rise times and decay times, were very similar. RS cell IPSCs evoked from both the somata $(n=8)$ and the apical dendrites $(n=5)$ had consistent rise and decay times. At some stimulation sites it was also possible to evoke IPSCs such that one could observe stimulation of a single fiber, followed by recruitment of additional fibers as stimulus strength was increased (Fig. $8 \mathrm{~A})$. However, it was nearly impossible to consistently activate only one fiber at the soma of a given RS neuron, while activation of multiple fibers on the apical dendrite was rarely observed (Fig. 8A). Minimally evoked IPSCs ranged from 200 to $400 \mathrm{pA}$, and total IPSC amplitudes ranged from 200 to $900 \mathrm{pA}$. Rise times and decay times did not vary systematically with amplitude. Rise times of minimally evoked events at the soma were similar to mIPSCs and sIPSCs (K-S test, $p<0.05$ ), but rise times of larger somatically evoked IPSCs were longer $(p<0.01)$. Decay times of RS cell somatically evoked IPSCs were fitted best to a single exponential. Because of the difference in ex- ponential fits, this result was not directly comparable to the mIPSC result. Dendritically evoked IPSCs (Fig. $8 \mathrm{~A}$ ) had very slow rise times which were significantly slower than mIPSCs, sIPSCs, and mIPSCs sucroseelicited from RS cell dendrites. Decay times of dendritically evoked IPSCs could be fitted to a single exponential, and they were usually slow and highly variable.

Similar results were seen in IB cells when IPSCs were evoked from the soma $(n=9)$ and the apical dendrite $(n=5) 50-60 \mu \mathrm{m}$ from the soma. Evoked IPSC amplitudes ranged from 100 to $800 \mathrm{pA}$, with minimally evoked IPSCs ranging from 90 to $400 \mathrm{pA}$. Isolation of a single fiber was not difficult at the somata of IB cells (Fig. 8B), but it was impossible in most IB cells to isolate a single fiber when stimulating the apical dendrite. Often, two to five fibers were seen (Fig. 8B). Rise time was not correlated with amplitude in either somatic or dendritic evoked IPSCs. Unlike RS cells, minimally evoked somatic IPSC rise times were faster than mIPSC rise times (K-S test, $p<0.01$ ). However, somatically evoked IPSCs in IB cells were kinetically indistinguishable from sucrose-elicited mIPSCs arising from the IB cell soma. Decay times were comparable to those observed in mIPSCs or sIPSCs and were fitted to a single exponential. Dendritically evoked IPSCs had relatively slow rise times and slow decay times. Both of these values are slower than mIPSCs, sIPSCs, and mIPSCs sucrose-evoked from the IB cell apical dendrite.

While dendritically evoked IPSCs were not significantly different in rise or decay time between cell types, RS cell somatically evoked IPSCs had signifi- 
A RS cell: soma

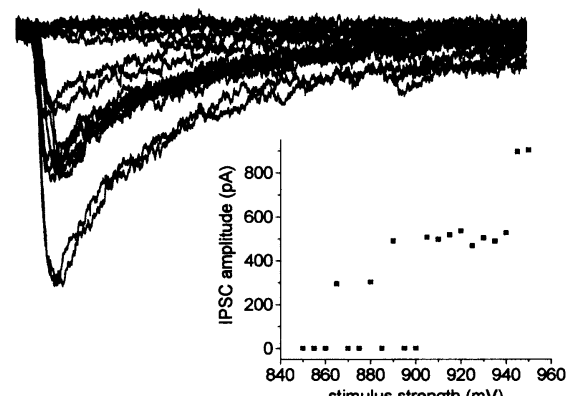

stimulus strength $(\mathrm{mV})$
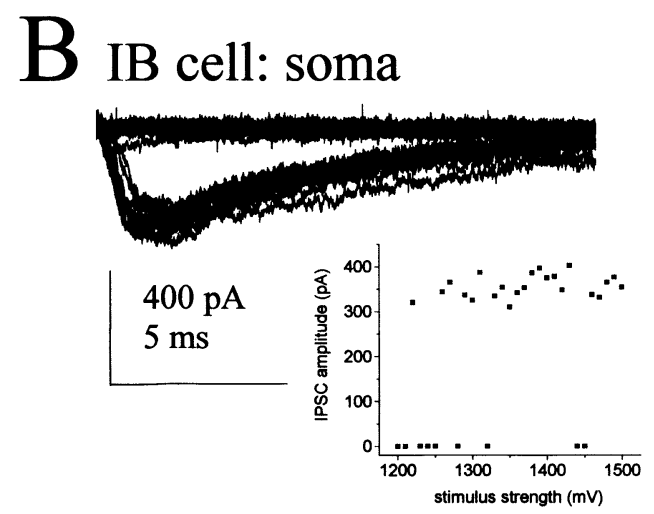

FIG. 8. A. RS cell-evoked IPSCs at the soma and apical dendrite. All current traces illustrated are subtracted from an averaged trace in which there was a stimulus artifact but no evoked IPSC (failures; see Methods for details). (Left) Evoked IPSCs at the soma are graded and probably represent recruitment of individual fibers. When stimuli were given in very small graded increments (inset below), a clear progression of input recruitment could be seen. (Right) It was more difficult to evoke IPSCs on the dendrite; two to three adjustments to electrode location were often needed to locate an afferent input. B. Synaptic IPSCs evoked from the soma and apical dendrite of IB cells. All current traces illustrated are subtracted from an averaged trace in

cantly faster rises $(\mathrm{K}-\mathrm{S}$ test, $p<0.01)$ and decays $(\mathrm{K}-\mathrm{S}$ test, $p<0.01)$ than somatically evoked IPSCs in IB cells. These evoked data also indicate that RS cell IPSCs arise somatically, while IB cell IPSCs arise dendritically and are consistent with the sucrose-elicited mIPSC data.

\section{DISCUSSION}

mIPSCs in layer $\mathrm{V}$ of auditory, visual, and somatosensory cortices

A surprising finding of our study is that mIPSCs in rat auditory cortex differ from those in other sensory cortical areas. Rise times of IPSCs were slightly faster while decay times of IPSCs in auditory cortical cells were far faster than those in somatosensory and visual cortices. Visual and somatosensory cortical mIPSCs recorded by us were similar to those measured in

\section{RS cell: dendrite}

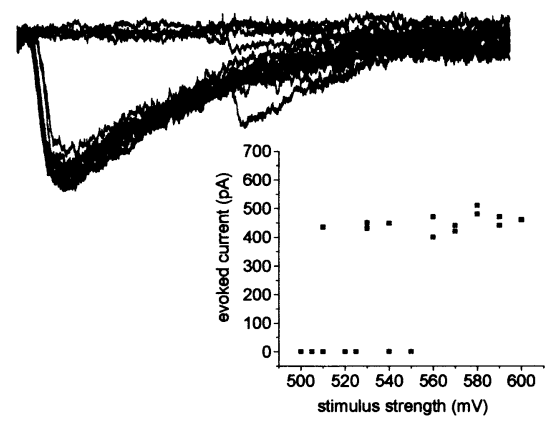

\section{IB cell: dendrite}

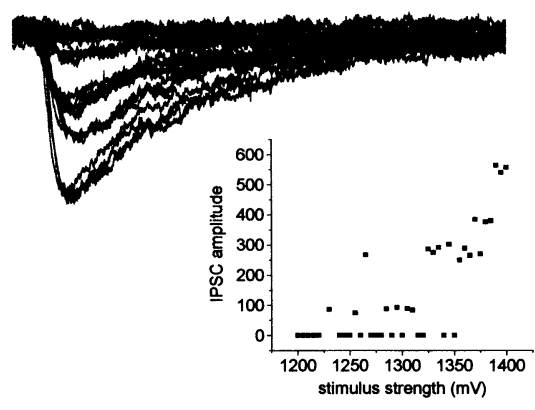

which there was no evoked IPSC (failures). (Left) Stimulation near the soma elicited IPSCs from single fibers. It was unusual to see recruitment of additional fibers during somatic stimulation (inset below). (Right) Stimulation of the apical dendrite $50 \mu \mathrm{m}$ distal from the soma always elicited IPSCs that were graded. These IPSCs could always be clearly grouped into successive recruited inputs (inset below). Often, fiber recruitment would occur until voltage-gated channels were activated, resulting in a loss of voltage clamp. It was usually possible to discern four to six inputs before loss of voltage clamp.

previous reports (Salin and Prince 1996; Xiang et al. 1998). Pyramidal cell decay times in hippocampus are also slower than those reported presently (Ropert et al. 1990; Otis et al. 1991, 1992, 1994; Banks et al. 1998). The only IPSCs with rise and decay kinetics comparable to those in the auditory cortex are IPSCs recorded in interneurons in the cerebellum (Bartos et al. 2001).

Why might the auditory cortex require such a difference in synaptic behavior? This is a very difficult question to answer at present given that we know very little about exactly what the auditory cortex is doing. We also do not know whether these rapid kinetics are specific to inhibitory inputs on cells in layer $\mathrm{V}$ or ubiquitous for all inhibitory inputs on all auditory cortical cells. Several cell types in the auditory brainstem have developed synaptic events with unusually rapid kinetics that seem to enhance the cells' abilities to accurately follow rapid sequences of auditory events. For example, cells receiving auditory nerve 
input in the mammalian cochlear nuclei have glutamatergic mEPSCs that are the fastest in the nervous system (Gardner et al. 1999). Such specializations may account for the ability of these cells to relay temporal information with great precision (Smith and Rhode 1987; Joris et al. 1994). However, these rapid kinetics are seen at excitatory glutamatergic synapses, not at GABAergic synapses where there are some reports of unusually slow kinetics (see Trussell 2002). In addition, the auditory cortex is not able to follow rapid sequences of auditory events, like clicks or the rhythmic periodicity in speech sounds, as well as its downstream structures. The most obvious conclusion is that the IPSC kinetics are faster in the auditory cortex because there are timing issues here that require a more accurate/faster rebound from inhibition. One idea that comes to mind is the encoding of rapid transients such as those found in syllables at the transition from stimulus onset to the onset of voicing. Recordings from the auditory cortex have shown that, at certain intervals between stimulus and voicing onset, there is a well-timed response peak at voicing onset but no further response (Steinschneider et al. 1994, 1995). Such a well-timed response might be realized by a release from inhibition. The mechanism for the fast kinetics of auditory cortical IPSCs is unknown. The auditory cortex may utilize a different set of GABA subunits, with different kinetics, than other cortical areas. This is not strongly supported by existing anatomical studies that show that GABA subunit staining is similar among cortical areas (Wisden et al. 1992; Fritschy and Mohler 1995; Fritschy et al. 1998). Additional experiments comparing mIPSC kinetics in other neocortical areas, $\mathrm{GABA}_{\mathrm{A}}$ receptor subunit composition, and interneuronal circuitry and synaptic release properties may explain this finding.

\section{Differences in mIPSCs observed in IB and RS cells of the auditory cortex}

Previous studies have established a correlation between cell type and inhibition in IB and RS cells. In vitro, IB cells have predominantly excitatory responses to stimulation of their synaptic inputs, while RS cells have mixed responses (Chagnac-Amitai and Connors 1989; Nicoll et al. 1996; Hefti and Smith 2000; Schubert et al. 2001). In vivo, IB cells have complex receptive fields in the visual cortex without strong inhibitory surrounds, while RS cells have visual receptive fields with prominent inhibition (Finlay et al. 1976; Swadlow 1988). Using intracellular GABA $_{A}$ blockade in slices (Hefti and Smith 2000), it was demonstrated that inhibition played a minor role in IB cell responses to synaptic stimulation but played a prominent role in RS cell synaptic responses, shunt- ing large excitatory inputs and often preventing action potential generation. Anatomical data (White et al. 1994), on the other hand, show that IB and RS neurons have similar numbers of inhibitory synaptic sites on their somata and proximal dendrites. The present study further investigates these findings using whole-cell voltage clamp techniques to address more quantitatively the question of inhibition in these two cell types.

The second major finding of this report is that RS and IB cells in auditory, visual, and somatosensory layer V have mIPSCs that vary in kinetics, amplitude, and rate. IB cell mIPSCs have slower rise times, different decay kinetics, and smaller amplitudes than RS cell mIPSCs, but they occur more frequently, at a rate of $31 \mathrm{~Hz}$ compared with $13 \mathrm{~Hz}$ for RS cells. The explanation best supported by these results is that IB cell mIPSCs are smaller and slower because they occur out on the dendrites and are electrically filtered as recorded at the soma. This was not supported by plots of rise time versus peak amplitude, which did not show evidence for dendritic filtering in IB cells or RS cells. A more rigorous method for determining the location of inhibitory terminals on these pyramidal cells was to focally apply sucrose either to the cell body or to the dendritic tree.

\section{Sucrose-elicited mIPSCs}

Experiments measuring mIPSCs and spontaneous IPSCs suggested that dendritic filtering could account for differences in mIPSC kinetics in RS and IB cells. We elicited focal increases in mIPSCs in auditory cortical cells at the soma and 50-60 $\mu \mathrm{m}$ from the soma on the apical dendrite using sucrose (Bekkers and Stevens 1996) to examine the kinetics of mIPSCs occurring at each site. We found that in RS cells, sucrose-elicited mIPSCs at the soma match those recorded under control conditions, while in IB cells, dendritic mIPSCs were the best match to control mIPSCs. Somatic RS cell mIPSCs also had faster rise times than somatic IB cell mIPSCs.

Two connected mechanisms may be at work to explain the different kinetics of RS and IB cell mIPSCs. First, most IB cell mIPSCs probably originate in the dendrites, while most RS cell mIPSCs originate at or near the soma. Dendritic filtering in IB cells probably accounts for part of the kinetic difference in the mIPSCs. Second, the inhibitory circuitry of these two cell types may differ. Even when not dendritically filtered, IB cell mIPSCs are kinetically different from RS cell mIPSCs. Different $\mathrm{GABA}_{\mathrm{A}}$ subunit compositions lead to different kinetic properties of the receptors (Verdoom 1994; Gingrich et al. 1995; Tia et al. 1996) and may account for the difference in the kinetics of IB and RS cell mIPSCs originating at the 
soma. Different classes of interneurons also tend to preferentially synapse on pyramidal cells at different locations. Some interneuronal types synapse on the soma or proximal dendrites, others on the axonal initial segment, and still others on distal dendrites (Kawaguchi and Kubota 1997; Thomson and Deuchars 1997). IB cells may receive their most active inputs from interneurons forming synapses on their dendrites, while RS cells receive their most active inputs from a different class of interaeuron on their somata. This might explain the difference in the locations of predominant spontaneous inputs to RS and IB cells and the differences in kinetics. Further experiments are necessary as neither anatomical nor physiological data are available to support or refute this hypothesis.

\section{Monosynaptic minimally evoked IPSCs}

Miniature and spontaneous IPSCs measure the kinetic properties of postsynaptic receptors at individual synapses. To study synaptic IPSCs, and confirm that their kinetics are similar to mIPSCs, we evoked IPSCs by stimulation of afferent fibers to each cell type at the soma and the apical dendrites. IPSCs evoked in a particular location had similar kinetics to sucrose-elicited mIPSCs arising from that same location within a given cell type. Somatically evoked IPSCs in IB cells had slower rises and decays than those evoked at the somata of RS cells.

The combined data indicate that RS and IB cells may receive different inputs, and they may process those inputs in fundamentally different ways. RS and IB cell IPSCs are kinetically distinct. They may express different $\mathrm{GABA}_{\mathrm{A}}$ receptors or receive inputs from different classes of interneuron, or both. A cell's synaptic inputs can influence the receptors it expresses postsynaptically, and a single cell can express different receptor subtypes (Brickley et al. 1999), supporting this hypothesis. The most active inputs to IB and RS cells are also localized to different parts of their anatomy. RS cells have their most active synapses at or near the soma, while IB cell active inputs are on the dendrites. This suggests that IB cells process more of their excitatory and inhibitory inputs locally, and excitation is probably shunted before reaching the cell body. RS cells, in contrast, may prevent action potential generation through somatic or axonal inhibition.

These data also address the anatomical finding that IB and RS neurons receive similar numbers of inhibitory synapses on their somata (White et al. 1994), while physiologically they differ in their effective inhibition (Chagnac-Amitai and Connors 1989; Nicoll et al. 1996; Hefti and Smith 2000; Schubert et al. 2001). Vesicle release and synaptic responses can be evoked from somatic synapses at approximately the same rate in each cell type. The difference lies in which synapses are most spontaneously active. If a presynaptic cell has a high spontaneous release rate, it also has a high release probability when an action potential is fired (Prange and Murphy 1999). The most highly active release sites are localized to the soma in RS cells and to the dendrites in IB cells. This may also be where the most active sites are in the intact system and explains the physiological finding that IB cells receive less apparent inhibition at their somata than RS cells, despite having similar numbers of synapses.

\section{ACKNOWLEDGMENTS}

This work was supported by NIH grants F31-00256 (BJH) and DC-00116 (PHS) and funds provided by a grant to the University of Wisconsin Medical School from the Howard Hughes Medical Institute Research Resources Program for Medical Schools. Thanks to Inge Siggelkow, Joan Meister, and Jo Ann Ekleberry for expert histological processing and Matt Banks for discussion of the manuscript.

\section{REFERENCES}

ADAMS JC. Heavy metal intensification of DAB-based HRP reaction product [letter] J. Histochem. Cytochem. 29:775, 1981.

Banks MI, Li TB, Pearce RA. The synaptic basis of $\mathrm{GABA}_{\mathrm{A}}$, slow. J. Neurosci. 18:1305-1317, 1998.

Barany A, Szente MB, Woody CD. Electrophysiological characterization of different types of neurons recorded in vivo in the motor cortex of the cat. I. Patterns of firing activity and synaptic responses. J. Neurophysiol. 69:1850-1864, 1993.

BARTH DS, Di S. Three-dimensional analysis of auditory-evoked potentials in rat neocortex. J. Neurophysiol. 64:1527-1536, 1990.

BARTH DS, Di S. The functional anatomy of middle latency auditory evoked potentials. Brain Res. 565:109-115, 1991.

Bartos M, Vida I, Frotscher M, Geiger JRP, Jonas P. Rapid signaling at inhibitory synapses in a dentate gyrus interneuron network. J. Neurosci. 21:2687-2698, 2001.

Bekkers JM, Stevens CF. Quantal analysis of EPSCs recorded from small numbers of synapses in hippocampal cultures. J. Neurophysiol. 73:1145-1156, 1995.

Bekkers JM, Stevens CF. Cable properties of cultured hippocampal neurons determined from sucrose-evoked miniature EPSCs. J. Neurophysiol. 75:1250-1255, 1996.

Bourassa J, Deschenes M. Corticothalamic projections from the primary visual cortex in rats: a single fiber study using biocytin as an anterograde tracer. Neuroscience 66:253-263, 1995.

Brickley SG, Cull-Candy SG, Farrant M. Single-channel properties of synaptic and extrasynaptic $\mathrm{GABA}_{\mathrm{A}}$ receptors suggest differential targeting of receptor subtypes. J. Neurosci. 19:2960-2973, 1999.

Chagnac-Amitai Y, Connors BW. Synchronized excitation and inhibition driven by intrinsically bursting neurons in neocortex. J. Neurophysiol. 62:1149-1162, 1989.

Chagnac-Amitai Y, Luhmann HI, Prince DA. Burst generating and regular spiking layer 5 pyramidal neurons of rat neocortex have different morphological features. J. Comp. Neurol. 296:598613, 1990. 
Cheng H, Мryamoto MD. Effect of hypertonicity on augmentation and potentiation and on corresponding quantal parameters of transmitter release. J. Neurophysiol. 81:1428-1431, 1999

Cipolloni PB, Peters A. The termination of callosal fibres in the auditory cortex of the rat. A combined Golgi-electron microscope and degeneration study. J. Neurocytol. 12:713-726, 1983.

Deschenes M, Bourassa J, Pinault D. Corticothalamic projections from layer $\mathrm{V}$ cells in rat are collaterals of long-range corticofugal axons. Brain Res. 664:215-219, 1994.

Di S, BARTH DS. The functional anatomy of middle-latency auditory evoked potentials: thalamocortical connections. J. Neurophysiol. 68:425-431, 1992.

Doucet JR, Rose L, Ryugo DK. The cellular origin of corticofugal projections to the superior olivary complex in the rat. Brain Res. 925:28-41, 2002.

Edwards FA, Konnerth A, Sakmann B, Takahashi T. A thin slice preparation for patch clamp recordings from neurones of the mammalian central nervous system. Pflugers Arch 414:600-612, 1988.

Finlay BL, Schiller PH, Volman SF. Quantitative studies of singlecell properties in monkey striate cortex. IV. Corticotectal cells. J. Neurophysiol. 39:1352-1361, 1976.

Fritschy JM, Mohler H. GABA A $^{-r e c e p t o r ~ h e t e r o g e n e i t y ~ i n ~ t h e ~ a d u l t ~}$ rat brain: differential regional and cellular distribution of seven major subunits. J. Comp. Neurol. 359:154-194, 1995.

Fritschy JM, Weinmann O, Wenzel A, Benke D. Synapse-specific localization of NMDA and $\mathrm{GABA}_{\mathrm{A}}$ receptor subunits revealed by antigen-retrieval immunohistochemistry. J. Comp. Neurol. 390:194-210, 1998.

GAMES KD, Winer JA. Layer V in rat auditory cortex: projections to the inferior colliculus and contralateral cortex. Hear Res. 34:125, 1988.

Gardner SM, Trussell LO, Oertel D. Time course and permeation of synaptic AMPA receptors in cochlear nuclear neurons correlate with input. J. Neurosci. 19:8721-8729, 1999.

Gingrich KJ, Roberts WA, Kass RS. Dependence of the $\mathrm{GABA}_{\mathrm{A}}$ receptor gating kinetics on the alpha-subunit isoform: implications for structure-function relations and synaptic transmission. J. Physiol. 489:529-543, 1995.

GUILLERY RW. Anatomical evidence concerning the role of the thalamus in corticocortical communication: a brief review. J. Anat. 187:583-592, 1995.

Hamill OP, Marty A, Neher E, Sakmann B, Sigworth FJ. Improved patch-clamp techniques for high-resolution current recording from cells and cell-free membrane patches. Pflugers Arch. 391:85-100, 1981.

Hefti BJ, Sмiтh PH. Anatomy, physiology, and synaptic responses of rat layer $\mathrm{V}$ auditory cortical cells and effects of intracellular $\mathrm{GABA}_{\mathrm{A}}$ blockade. J. Neurophysiol. 83:2626-2638, 2000.

Joris PX, SMITH PH, YIN TC. Enhancement of neural synchronization in the anteroventral cochlear nucleus. II. Responses in the tuning curve tail. J. Neurophysiol. 71:1037-1051, 1994.

Kasper EM, Larkman AU, Lubke J, Blakemore C. Pyramidal neurons in layer 5 of the rat visual cortex. I. Correlation among cell morphology, intrinsic electrophysiological properties, and axon targets. J. Comp. Neurol. 339:459-474, 1994.

KaWAGUChi Y, Kubota Y. GABAergic cell subtypes and their synaptic connections in rat frontal cortex. Cereb. Cortex 7:476-486, 1997.

Mascagni F, Mcdonald AJ, Coleman JR. Corticoamygdaloid and corticocortical projections of the rat temporal cortex: a Phaseolus vulgaris leucoagglutinin study. Neuroscience 57:697-715, 1993.

Morizumi T, Hattori T. Pyramidal cells in rat temporoauditory cortex project to both striatum and inferior colliculus. Brain Res. Bull. 27:141-144, 1991.
Nicoll A, Kim HG, Connors BW. Laminar origins of inhibitory synaptic inputs to pyramidal neurons of the rat neocortex. J. Physiol. 497:109-117, 1996.

Nunez A, Amzica F, Steriade M. Electrophysiology of cat association cortical cells in vivo: intrinsic properties and synaptic responses. J. Neurophysiol. 70:418-430, 1993.

OJIMA H. Teminal morphology and distribution of corticothalamic fibers originating from layers 5 and 6 of cat primary auditory cortex. Cereb. Cortex 4:646-663, 1994.

OJIMA H, HoNDA CN, JoNEs EG. Characteristics of intracellularly injected infragranular pyramidal neurons in cat primary auditory cortex. Cereb. Cortex 2:197-216, 1992.

Otis TS, Staley KJ, Mody I. Perpetual inhibitory activity in mammalian brain slices generated by spontaneous GABA release. Brain Res. 545:142-150, 1991.

OTIS TS, DE Koninck Y, Mody I. Lasting potentiation of inhibition is associated with an increased number of gamma-aminobutyric acid type A receptors activated during miniature inhibitory postsynaptic currents. Proc. Natl. Acad. Sci. USA 91:7698-7702, 1994.

OTIS TS, Mody I. Modulation of decay kinetics and frequency of $\mathrm{GABA}_{\mathrm{A}}$ receptor-mediated spontaneous inhibitory postsynaptic currents in hippocampal neurons. Neuroscience 49:13-32, 1992.

Paxinos G, Watson C. The Rat Brain in Stereotaxic Coordinates. Academic Press, Orlando FL, 1986,

Prange O, Murphy TH. Correlation of miniature synaptic activity and evoked release probability in cultures of cortical neurons. J. Neurosci. 19:6427-6438, 1999.

Ropert N, Miles R, Korn H. Characteristics of miniature inhibitory postsynaptic currents in CA1 pyramidal neurones of rat hippocampus. J. Physiol. 428:707-722, 1990.

Rosenmund C, Stevens CF. Definition of the readily releasable pool of vesicles at hippocampal synapses. Neuron 16:1197-1207, 1996.

Ruttgers K, Aschoff A, Friauf E. Commissural connections between the auditory cortices of the rat. Brain Res. 509:71-79, 1990.

SAlin PA, Prince DA. Spontaneous $\mathrm{GABA}_{\mathrm{A}}$ receptor-mediated inhibitory currents in adult rat somatosensory cortex. J. Neurophysiol. 75:1573-1588, 1996

Schubert D, Staiger JF, Cho N, Kotter R, Zilles K, Luhmann HJ. Layer-specific intracolumnar and transcolumnar functional connectivity of layer $\mathrm{V}$ pyramidal cells in rat barrel cortex. $\mathrm{J}$. Neurosci. 21:3580-3592, 2001.

SMith PH, Rhode WS. Characterization of HRP-labeled globular bushy cells in the cat anteroventral cochlear nucleus. J. Comp. Neurol. 266:360-375, 1987.

Steinschneider M, Schroeder CE, Arezzo JC, Vaughan Jr HG. Speech-evoked activity in primary auditory cortex: effects of voice onset time. Electroencephalogr. Clin. Neurophysiol. 92:30-43, 1994.

Steinschneider M, Schroeder CE, Arezzo JC, Vaughan Jr HG. Physiologic correlates of the voice onset time boundary in primary auditory cortex (A1) of the awake monkey: temporal response patterns. Brain Lang. 48:326-240, 1995.

SWADLOW HA. Efferent neurons and suspected interneurons in binocular visual cortex of the awake rabbit: receptive fields and binocular properties. J. Neurophysiol. 59:1162-1187, 1988.

Thomson AM, Deuchars J. Synaptic interactions in neocortical local circuits: dual intracellular recordings in vitro. Cereb. Cortex 7:510-522, 1997

Tia S, WANG JF, Kotchabhakdi N, Vicini S. Distinct deactivation and desensitization kinetics of recombinant $\mathrm{GABA}_{\mathrm{A}}$ receptors. Neuropharmacology 35:1375-1382, 1996.

Trussell LO. Cellular mechanisms for information coding in auditory brainstem nuclei. In: Oertel D, Popper AN, FAy RR (eds) 
Mammalian Auditory Pathways: Structure and Function. New York, Springer-Verlag, 2002, Chap 3 pp 72-98

VAUGHAN DW. Thalamic and callosal connections of the rat auditory cortex. Brain Res. 260:181-189, 1983.

VERDOORN TA. Formation of heteromeric gamma-aminobutyric acid type A receptors containing two different alpha subunits. Mol. Pharmacol. 45:475-480, 1994.

Vyklisky JR L, Patneau DK, Mayer ML. Modulation of excitatory synaptic transmission by drugs that reduce desensitization at AMPA/kainate receptors. Neuron 7:971-984, 1991.

WeEdman DL, Ryugo DK. Pyramidal cells in primary auditory cortex project to cochlear nucleus in rat. Brain Res. 706:97-102, 1996a.
Weedman DL, Ryugo DK. Projections from auditory cortex to the cochlear nucleus in rats: synapses on granule cell dendrites. J. Comp. Neurol. 371:311-324, 1996b.

White EL, Amitai Y, Gutnick MJ. A comparison of synapses onto the somata of intrinsically bursting and regular spiking neurons in layer V of rat SmI cortex. J. Comp. Neurol. 342:1-14, 1994.

Wisden W, Laurie DJ, Monyer H, Seeburg PH. The distribution of $13 \mathrm{GABA}_{\mathrm{A}}$ receptor subunit mRNAs in the rat brain. I. Telencephalon, diencephalon, mesencephalon. J. Neurosci. 12:10401062, 1992.

Xiang Z, Huguenard JR, Prince DA. GABA $\mathrm{A}_{\mathrm{A}}$ receptor-mediated currents in interneurons and pyramidal cells of rat visual cortex. J. Physiol. 506:715-730, 1998. 